\title{
Anti-tumor effect and influence of Gekko gecko Linnaeus on the immune system of sarcoma 180-bearing mice
}

\author{
QI YOU ${ }^{*}$, SHIYU HAN ${ }^{2 *}$, YUANLONG ZHANG ${ }^{3}$ and JIANHUA ZHENG ${ }^{1}$ \\ ${ }^{1}$ Department of Gynecology and Obstetrics, The First Affiliated Hospital of Harbin Medical University, \\ ${ }^{2}$ The Fourth Affiliated Hospital of Harbin Medical University, Heilongjiang 150001; \\ ${ }^{3}$ Harbin Red Cross Central Hospital, Heilongjiang 150076, P.R. China
}

Received August 8, 2008; Accepted March 16, 2009

DOI: $10.3892 / \mathrm{mmr} 00000139$

\begin{abstract}
Gekko gecko Linnaeus (GgL) is an extract used in traditional Chinese medicine. In the present study, we examined the anti-tumor activity of $\mathrm{GgL}$ and its effect on the immune system of mice. Sarcoma 180-bearing mice were used as the animal model, and cisplatin was applied as the positive control drug. The mice were randomly divided into six groups, and each group was treated with a different drug or drug concentration. The effects of $\mathrm{GgL}$ were evaluated based on its anti-tumor activity and prolongation of the lifespan, the lymphocyte transformation rate and pathological changes observed in the tumors. The results suggest that $\mathrm{GgL}$ has antitumor activities and up-regulates the immune system in a dosedependent manner. This study provides original data related to the anti-tumor and immune up-regulating function of $\mathrm{GgL}$.
\end{abstract}

\section{Introduction}

Chemotherapy is one of the main clinically-applied cancer treatments. Most chemotherapeutic drugs are cytotoxic; they not only kill tumor cells, but also simultaneously normal cells, causing numerous side effects $(1,2)$. With the ongoing exploration of traditional medical resources, doctors are placing increasing emphasis on traditional medicine-assisted treatment, which has shown an applicable foreground $(3,4)$.

Gekko gecko Linnaeus (GgL) is an extract commonly used in traditional Chinese medicine that is considered to be effective based on clinical and medical scientific research. In China, clinical and basic pharmacological research on GgL has been extremely active since the beginning of this century.

Correspondence to: Dr Jianhua Zheng, Department of Gynecology and Obstetrics, The First Affiliated Hospital of Harbin Medical University, Heilongjiang 150001, P.R. China

E-mail: yqvicky2006@hotmail.com

${ }^{*}$ Contributed equally

Key words: Gekko gecko Linnaeus, traditional medicine, anti-tumor, immune
GgL is used to treat liver and kidney deficiencies, and to relieve cough and asthma (5). It also has anti-tumor activities, on which little research has been conducted to date.

We set up an ovarian cancer model using sarcoma 180bearing $\left(S_{180}\right)$ mice, with which we investigated the effects of various doses of $\mathrm{GgL}$ on tumor formation and the immune system. The results provide a foundation for further toxicological and clinical research on GgL.

\section{Materials and methods}

Tumor cells and implantation procedure. $\mathrm{S}_{180}$ tumor cells were provided by the Tumor Specialty Hospital of Harbin Medical University. The cells were injected into the hind leg muscle of 108 4-week-old female nude BALB/c mice (2-3x105 cells per animal). The study protocol was approved by the Ethics Committee of Harbin Medical University, P.R. China.

Group formation and drug administration protocols. Tumorimplanted mice were randomly divided into six groups, treated as follows: group 1, sodium chloride solution; group 2, low-dose GgL (2.4 g/kg); group 3, high-dose GgL (12.4 g/kg); group 4 , cisplatin + sodium chloride solution; group 5 , cisplatin + low-dose GgL (2.4 g/kg); group 6, cisplatin + high-dose $\mathrm{GgL}(12.4 \mathrm{~g} / \mathrm{kg})$. GgL was administered i.g. at $0.4 \mathrm{mg} /$ day for 10 days. Cisplatin was administered i.p. at $7 \mathrm{mg} / \mathrm{kg}$ just once, $24 \mathrm{~h}$ after tumor cell injection.

Sample collection. On day 11, the surviving mice were sacrificed. The tumor mass was immediately removed and weighed, and the anti-tumor effect was evaluated. Spleen samples were obtained and the spleen index was calculated, and the lymphocyte transformation rate was measured using the MTT assay (6). Optical and electron microscopy were used to determine the pathological characteristics and changes in the tumor and spleen samples.

Analysis of the anti-tumor rate. Tumors were weighed and the t-test was performed using the average weight of each group. The anti-tumor rate was analyzed using the formula: antitumor rate $=\left(\mathrm{W}_{\mathrm{c}}-\mathrm{W}_{\mathrm{d}}\right) / \mathrm{W}_{\mathrm{d}} \times 100 \%$, where $\mathrm{W}_{\mathrm{c}}$ is the weight of the tumor mass of the control group and $\mathrm{W}_{\mathrm{d}}$ is the weight of the tumor mass of the experimental drug groups. 
Table I. Prolongation of lifespan by Gekko gecko Linnaeus.

\begin{tabular}{|c|c|c|c|}
\hline Group & No. of animals & Survival time (days) & Life extension rate $(\%)$ \\
\hline Sodium chloride solution 18 & $13.22 \pm 4.99$ & & \\
\hline Low-dose GgL & 18 & $16.78 \pm 4.98$ & 21.22 \\
\hline High-dose GgL & 18 & $18.06 \pm 4.09$ & 26.80 \\
\hline Cisplatin + sodium chloride & 18 & $19.17 \pm 3.27$ & 31.04 \\
\hline Cisplatin + low-dose GgL & 18 & $20.83 \pm 4.41$ & $36.53^{\mathrm{a}}$ \\
\hline Cisplatin + high-dose GgL & 18 & $21.89 \pm 4.20$ & $39.61^{\mathrm{a}}$ \\
\hline
\end{tabular}

${ }^{\mathrm{a}} \mathrm{p}<0.05$ compared with the sodium chloride group. Survival time is presented as the means $\pm \mathrm{SD}$.

Table II. Anti-tumor effect of Gekko gecko Linnaeus.

\begin{tabular}{|c|c|c|c|c|c|}
\hline \multirow[b]{2}{*}{ Group } & \multirow{2}{*}{$\begin{array}{l}\text { No. of } \\
\text { animals }\end{array}$} & \multicolumn{2}{|c|}{ Weight (g) } & \multirow{2}{*}{$\begin{array}{c}\text { Tumor weight } \\
(\mathrm{g})\end{array}$} & \multirow{2}{*}{$\begin{array}{c}\text { Tumor inhibitory } \\
\text { rate }(\%)\end{array}$} \\
\hline & & Start & End & & \\
\hline Sodium chloride solution & 8 & $18.025 \pm 0.419$ & $21.825 \pm 1.076$ & $5.013 \pm 0.463$ & - \\
\hline Low-dose GgL & 8 & $18.063 \pm 0.941$ & $23.825 \pm 2.981$ & $3.713 \pm 0.203$ & 25.94 \\
\hline High-dose GgL & 7 & $18.043 \pm 1.859$ & $25.300 \pm 1.269$ & $3.186 \pm 0.195$ & 36.44 \\
\hline Cisplatin + sodium chloride & 7 & $18.043 \pm 0.408$ & $14.329 \pm 0.507$ & $2.057 \pm 0.190$ & 58.96 \\
\hline Cisplatin + low-dose GgL & 8 & $18.125 \pm 1.135$ & $19.888 \pm 2.220$ & $1.863 \pm 0.167$ & $62.84^{\mathrm{a}}$ \\
\hline Cisplatin + high-dose GgL & 7 & $18.129 \pm 0.346$ & $20.329 \pm 0.331$ & $1.729 \pm 0.160$ & $65.51^{\mathrm{a}}$ \\
\hline
\end{tabular}

${ }^{\mathrm{a}} \mathrm{p}<0.01$ compared with the sodium chloride group. Weights are presented as the means $\pm \mathrm{SD}$.

Analysis of the life extension rate. As a control, a second set of 108 4-week-old female nude BALB/c mice, injected with control cells that had been cultured normally, was randomly divided into 6 groups and subjected to a drug administration regime identical to the one described above. The quality of life and lifespan of the mice were noted and compared to those of the experimental groups. The life extension rate was calculated using the formula: life extension rate $=\left(\mathrm{T}_{\mathrm{d}}-\mathrm{T}_{\mathrm{c}}\right) / \mathrm{T}_{\mathrm{d}} \times 100 \%$, where $T_{d}$ is the lifespan of the experimental groups and $T_{c}$ is the lifespan of the control group.

Spleen weight and calculation of the spleen index. Spleen samples were obtained aseptically and weighed. The spleen index was calculated using the formula: spleen index $=$ spleen weight/body weight.

Calculation of the lymphocyte transformation rate. MTT (Invitrogen) was used to calculate the lymphocyte transformation rate according to the manufacturer's instructions. On day 11 , the surviving mice were sacrificed and sterilized with $75 \%$ alcohol. Spleen samples were collected and placed in petri dishes with a glass cover slip containing Hank's solution (Invitrogen). The samples were then smoothly ground with a stainless steel sieve to produce a single-cell suspension fluid, which was transferred to a closed aseptic test tube. Cells were washed in Hank's solution then centrifuged at $1100 \mathrm{rpm}$ for $10 \mathrm{~min}$. This step was repeated three times, then the cells were resuspended in Hank's solution. The number of cells was adjusted to $1 \times 10^{6} / \mathrm{ml}$. The cell suspension fluid was distributed in 96-well petri dishes (100 $\mu \mathrm{l} /$ well in 4 wells). Concanavalin A (ConA) $(5 \mu \mathrm{g} / \mathrm{ml})$ (Invitrogen) and lipopolysaccharide (LPS) $(10 \mu \mathrm{g} / \mathrm{ml})$ (Invitrogen) were respectively added to 2 wells of the dish. The other 2 wells served as the control. The cells were incubated at $37^{\circ} \mathrm{C}$ with $5 \%$ humidified $\mathrm{CO}_{2}$ for $36 \mathrm{~h}$. Four hours before the end of the incubation period, $50 \mu \mathrm{l}$ MTT ( $5 \mathrm{~g} / \mathrm{l})$ was added to each well. Following incubation, the medium was replaced with acid isopropanol and the mixture was agitated until the purple crystals dissolved. Absorbance (OD) was measured at $570 \mathrm{~nm}$ using a 550 Microplate reader, and the lymphocyte transformation rate was calculated.

Statistical analysis. Data were analyzed using SPSS statistical analysis software.

\section{Results}

Prolongation of the lifespan. Following drug administration, the respiration and activity of the mice in the tumor groups were normal, with the exception of group 1, which was administered a sodium chloride solution. Mice in this group were weak and short of breath; they were reluctant to move and their fur was thin and dark. The average survival time of groups 5 and 6 (cisplatin + high- and low-dose GgL) was markedly increased compared to that of group $1(\mathrm{p}<0.05)$, but was no different compared to the survival time of group 4 $($ cisplatin + sodium chloride solution $)(\mathrm{p}>0.05)($ Table I). 

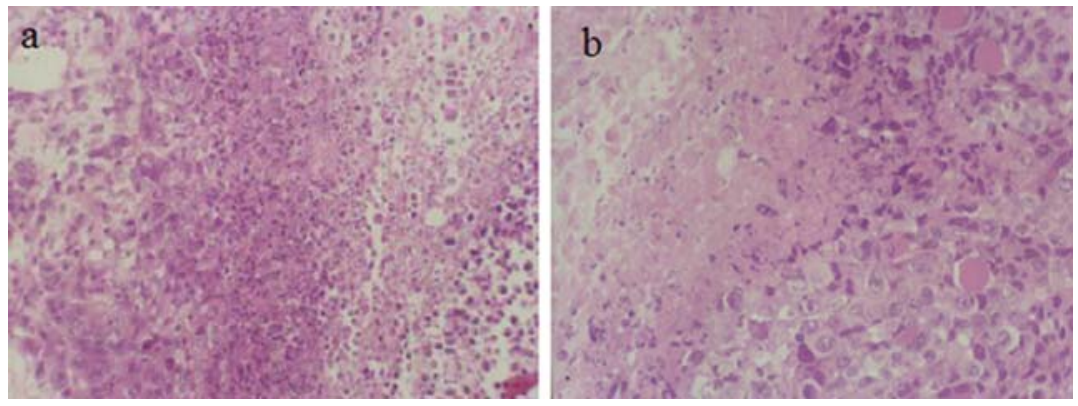

Figure 1. Representative lymphoid tumor of the (a) cisplatin + sodium chloride group (x200) and (b) cisplatin + GgL group (x400) using optical microscopy.
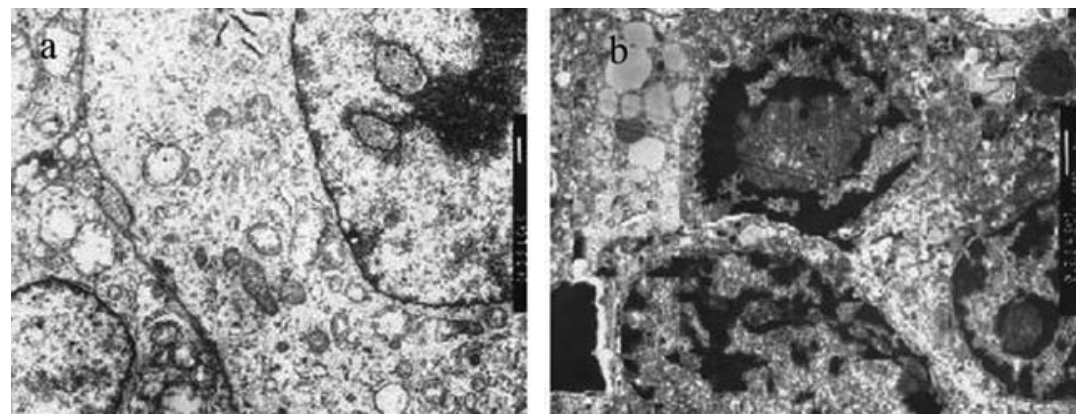

Figure 2. Representative lymphoid tumor of the (a) cisplatin + sodium chloride group (x10K) and (b) cisplatin + GgL group (x8000) using electron microscopy.

Table III. Effects on the immune system of Gekko gecko Linnaeus.

\begin{tabular}{lccc}
\hline Group & No. of animals & Average spleen weight $(\mathrm{g})$ & Spleen index \\
\hline Sodium chloride solution & 8 & $1.953 \pm 0.017$ & $8.98 \pm 0.78$ \\
Low-dose GgL & 8 & $1.979 \pm 0.019$ & $8.31 \pm 0.10$ \\
High-dose GgL & 7 & $2.030 \pm 0.048$ & $8.01 \pm 0.25^{\mathrm{a}}$ \\
Cisplatin + sodium chloride & 7 & $1.840 \pm 0.027$ & $12.87 \pm 0.32$ \\
Cisplatin + low-dose GgL & 8 & $1.911 \pm 0.036$ & $9.61 \pm 0.15$ \\
Cisplatin + high-dose GgL & 7 & $1.913 \pm 0.011$ & $9.41 \pm 0.37$ \\
\hline
\end{tabular}

${ }^{\mathrm{a}} \mathrm{p}<0.05$ compared with the cisplatin + sodium chloride group. Data are presented as the means $\pm \mathrm{SD}$.

Anti-tumor activities. Following treatment with cisplatin and $\mathrm{GgL}$, the tumor growth rate was markedly reduced. The antitumor rates of group 3 (high-dose $\mathrm{GgL}$ ) and group 4 (cisplatin + sodium chloride solution) were 36.44 and $58.96 \%$, respectively, and were significantly different compared to group 1 . The anti-tumor rates of groups 5 and 6 were 62.84 and $65.51 \%$, respectively, and were significantly different compared to group 1. However, the anti-tumor rates of groups 5 and 6 were not significally different compared to group 4 . The results indicate that GgL has an anti-tumor effect which tends to be enhanced with an increase in its concentration, and that it can strengthen the curative effect of cisplatin (Table II).

Lymphoid tumor pathology. Optical and electron microscopy were used to examine the characteristics of the tumor cells. Using optical microscopy, groups 5 and 6 were observed to have a few tumor cells mixed with necrotic foci in the tumor mass, along with large areas of solidified necrosis (Fig. 1).
Using electron microscopy, apoptosis was observed in the tumor cells of groups 5 and 6 . In addition, the nuclei appeared solidified and shrunken, and the nuclear membranes were incomplete. Mitochondrial vacuolation was observed, and the endoplasmic reticulum was clearly visible (Fig. 2). These results indicate that tumor necrosis was more severe in groups 5 and 6 than in group 4.

Spleen weights and index. The spleens of mice in groups 2 and 3 (low- and high-dose GgL) were heavier than those of mice in group 1, while the spleens of mice in group 1 were heavier than those of group 4. The spleens of mice in groups 5 and 6 were also heavier than those of group 4, although without statistical significance. Additionally, the spleen index of group 3 was significantly lower than that of group 4, and was even slightly lower than that of group 1 . This indicates that GgL strengthens the immune system, an effect which is enhanced with an increase in its concentration (Table III). 

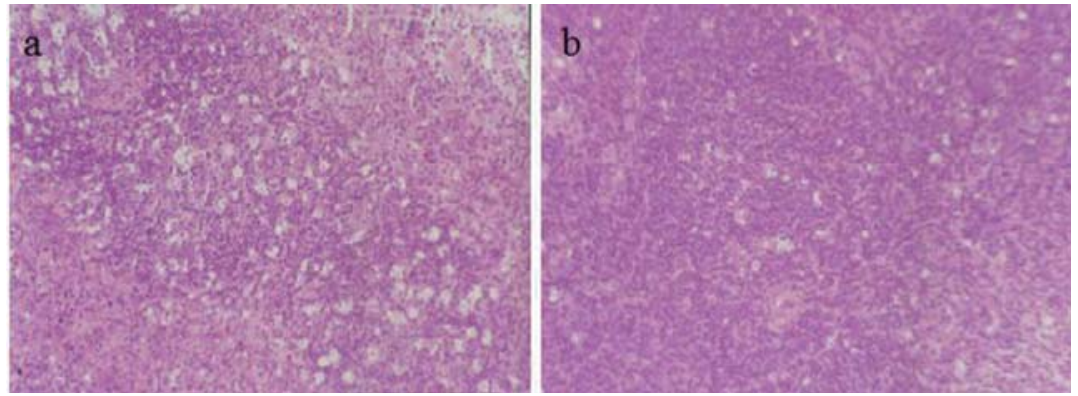

Figure 3. Representative spleen of the (a) cisplatin + sodium chloride group (x200) and (b) cisplatin + GgL group (x200) using optical microscopy.

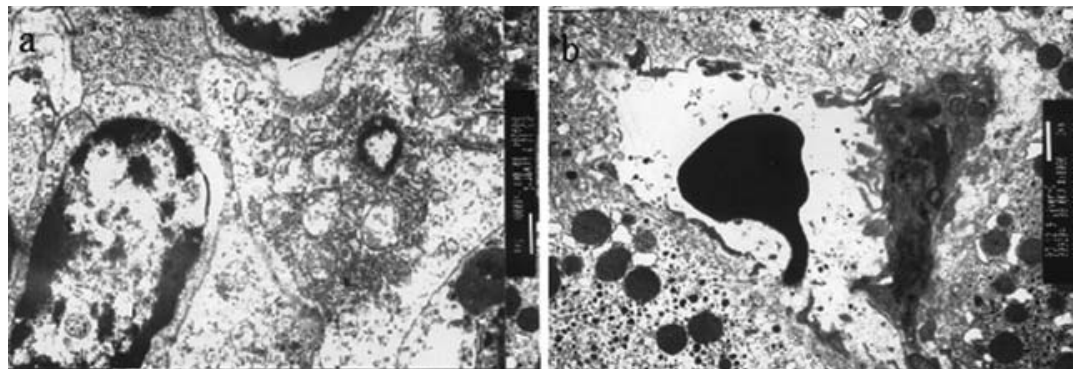

Figure 4. Representative spleen of the (a) cisplatin + sodium chloride group (x10K) and (b) cisplatin + GgL group (x8000) using electron microscopy.

Table IV. Lymphocyte transformation.

\begin{tabular}{lccc}
\hline Group & No. of animals & ConA & LPS \\
\hline Sodium chloride solution & 8 & $1.176 \pm 0.014$ & $1.150 \pm 0.019$ \\
Low-dose GgL & 8 & $1.200 \pm 0.013^{\mathrm{a}}$ & $1.170 \pm 0.011^{\mathrm{a}}$ \\
High-dose GgL & 7 & $1.220 \pm 0.022^{\mathrm{b}}$ & $1.200 \pm 0.014^{\mathrm{b}}$ \\
Cisplatin + sodium chloride & 7 & $0.967 \pm 0.060$ & $0.760 \pm 0.024$ \\
Cisplatin + low-dose GgL & 8 & $1.050 \pm 0.018$ & $1.070 \pm 0.017$ \\
Cisplatin + high-dose GgL & 7 & $1.130 \pm 0.026$ & $1.150 \pm 0.018$ \\
\hline
\end{tabular}

${ }^{\mathrm{a}} \mathrm{p}<0.05$ and ${ }^{\mathrm{b}} \mathrm{p}<0.01$ compared with the cisplatin + sodium chloride group. Data are presented as the means $\pm \mathrm{SD}$. ConA, Concanavalin A; LPS, lipopolysaccharide.

Spleen pathology. Optical and electron microscopy were used to examine changes in the spleen samples. Using optical microscopy, lymphocyte apoptosis and activated macrophages were observed in groups 5 and 6, though to a lesser degree than in group 4 (Fig. 3). Using electron microscopy, groups 5 and 6 were observed to have well developed spleen cells, and red pulp and splenic corpuscles with normal structures. Nuclei were normal, and nucleons were clear. A large number of well-developed mitochondria were observed around the nucleus, and only a few catkin-like foci were present in the cytoplasm. In contrast, in group 4, the nuclear envelope was unclear, heterochromatin was marginalized to the edge of the nucleus and nuclei were solidified and shrunken (Fig. 4).

Lymphocyte transformation. With the addition of induction reagents, lymphocytes were converted to lymphoblasts, which proliferated and released lymphoid factors. As induction reagents, ConA for the most part induced the proliferation of $\mathrm{T}$ lymphocytes, while LPS mainly induced the proliferation of B lymphocytes. Cisplatin had a strong inhibitory effect on the proliferation of $\mathrm{T}$ and $\mathrm{B}$ lymphocytes in the spleen tissues $(\mathrm{p}<0.01)$, while $\mathrm{GgL}$ promoted their proliferation. There was significant difference in lymphocyte proliferation between group 1 and groups 2 and 3, with higher concentrations of GgL having an enhanced effect. These results indicate that GgL can markedly strengthen the immune response induced by $\mathrm{T}$ or B lymphocytes (Table IV).

\section{Discussion}

Malignant ovarian tumors are the third most commonly occuring female reproductive system tumors, but are first in terms of mortality (7). This is primarily due to the lack of a specific tumor marker for the cancer, and to the fact that patients in the early stages of the disease don't present obvious symptoms, making early diagnosis a challenge (8).

At the time of diagnosis, approximately $70 \%$ of patients are in the late stages of ovarian cancer. However, with the rapid 
development of new medical techniques, including the emergence of B ultrasounds, CT scans, peritoneoscopy, MRI and PET scans, and laboratory examinations being conducted in all fields, the number of cases of ovarian cancer diagnosed and treated at an early stage has the potential to increase, with associated improvements in survival rate $(9,10)$.

In China, malignant ovarian tumors are most commonly treated by surgery, with the additional administration of chemotherapy and radiotherapy regimes. However, the development of biological therapy (immunotherapy) would greatly benefit patients (11). Tumor occurrence and development are associated with the down-regulation of the immune system (12). In normal situations, cells and the body defense system are balanced. When this balance is disrupted, tumors form, proliferate and metastasize. Thus, theoretically, if the unbalanced immune system is returned to its normal state, tumor cell proliferation will be inhibited.

The immune system of ovarian cancer patients is unbalanced; during the later stages of the disease, almost all normal immune reactions are suppressed, so the drugs used in chemotherapy not only kill tumor cells, but also destroy the body's immune system (13). As the extent of immune system downregulation varies from patient to patient, monitoring immunochemical data throughout treatment is necessary to guide and restructure the therapeutic plan and improve patient prognosis.

Chemotherapy is one of the most commonly applied and important cancer treatments. However, it is rejected by many patients due to its serious side effects, negatively affecting treatment. The administration of traditional Chinese medicines in conjunction with chemotherapy has the potential to relieve side effects and toxicity, and to enhance the function of the immune system $(14,15)$.

In the present study, GgL was applied as a biological mediator of immune response. We studied the anti-tumor effect of different doses of $\mathrm{GgL}$ on tumors and the spleen, an organ indicative of the state of the immune system. GgL promoted the apoptosis of tumor cells, improved the quality of life and prolonged the lifespan of the mice in our model, suggesting it inhibits tumor proliferation and improves the balance of the immune system.

The functioning of the immune system is closely related with the condition of organs such as the spleen. Some immunosuppressants, such as cisplatin, can cause spleen atrophy, while immune enhancers can increase spleen weight. Thus, the spleen can serve as an experimental indicator of the condition of the immune system.

The results of the present study indicate that GgL significantly reduced a spleen index abnormally increased by the administration of cisplatin, even to the levels of a tumorbearing group administered a sodium chloride solution. Additionally, $\mathrm{GgL}$ enhanced the transformation of $\mathrm{T}$ and $\mathrm{B}$ lymphocytes, suggesting that it inhibits tumor cell activity by strengthening the immune system. GgL may primarily affect the monitoring function of the immune system as well as $\mathrm{T}$ and B lymphocyte-mediated immune response. It is well known that activated $\mathrm{T}$ and $\mathrm{B}$ lymphocytes are capable of directly killing tumor cells. In addition, they can produce a series of lymphoid factors that, together with macrophages, induce apoptosis and inhibit the proliferation of tumor cells. This is one aspect of cancer immunotherapy.
In conclusion, GgL can be used as a supplementary drug in clinical chemotherapy for malignant tumors, functioning as a tumor inhibitor and up-regulating the immune system. In further experiments, we will continue to investigate the functions and mechanism of $\mathrm{GgL}$, with the aim of demonstrating its utility as an effective cancer treatment.

\section{Acknowledgements}

This work was supported by the First Affiliated Hospital of Harbin Medical University Scientific Research Fund (no. 2007092), the Scientific Fund of the Department of Health of Heilongjiang Province (no. 2007-205) and by the Heilongjiang Natural Science Foundation (no. D200805).

\section{References}

1. Yeung BH, Wong KY, Lin MC, et al: Chemosensitisation by manganese superoxide dismutase inhibition is caspase- 9 dependent and involves extracellular signal-regulated kinase $1 / 2$. Br J Cancer 99: 283-293, 2008.

2. Tanaka T, Toujima S, Utsunomiya T, Yukawa K and Umesaki N: Experimental characterization of recurrent ovarian immature teratoma cells after optimal surgery. Oncol Rep 20: 13-23, 2008.

3. Takai N, Ueda T, Nishida M, Nasu K and Narahara H: Bufalin induces growth inhibition, cell cycle arrest and apoptosis in human endometrial and ovarian cancer cells. Int J Mol Med 21: 637-643, 2008.

4. Zhang Y, Hu YL and Cheng YY: Docetaxel influences autocrine of transforming growth factors and induces apoptosis in human ovarian cancer cell line AO. Chin Med Sci J 21: 204, 2006.

5. Hiramatsu N, Hara A, Hiramatsu K, et al: Vitellogenin-derived yolk proteins of white perch, Morone americana: purification, characterization, and vitellogenin-receptor binding. Biol Reprod 67: 655-667, 2003.

6. Yang H, Bhat GK and Sridaran R: Clinostat rotation induces apoptosis in luteal cells of the pregnant rat. Biol Reprod 66: 770-777, 2002.

7. Yang L, Klint A, Lambe M, Bellocco R, Riman T, Bergfeldt K, Persson I and Weiderpass E: Predictors of ovarian cancer survival: a population-based prospective study in Sweden. Int J Cancer 123: 672-679, 2008.

8. Urban $\mathrm{N}$ and Drescher C: Potential and limitations in early diagnosis of ovarian cancer. Adv Exp Med Biol 622: 3-14, 2008.

9. Eliassen $\mathrm{AH}$ and Hankinson SE: Endogenous hormone levels and risk of breast, endometrial and ovarian cancers: prospective studies. Adv Exp Med Biol 630: 148-165, 2008.

10. Milam RA, Milam MR and Iyer RB: Detection of early-stage ovarian cancer by FDG-PET-CT in a patient with BRCA2-positive breast cancer. J Clin Oncol 25: 5657-5658, 2007.

11. Weide R, Arndt M, Pandorf A, Heymanns J, Thomalla J and Köppler H: Ovarian cancer treatment reality in northern RheinlandPfalz. Suboptimal surgical treatment as a possible cause for inferior survival. Onkologie 30: 611-617, 2007.

12. Krockenberger M, Dombrowski Y, Weidler C, et al: Macrophage migration inhibitory factor contributes to the immune escape of ovarian cancer by down-regulating NKG2D. J Immunol 180: 7338-7348, 2008

13. Padjas A, Lesisz D, Lankoff A, et al: Cytogenetic damage in lymphocytes of patients undergoing therapy for small cell lung cancer and ovarian carcinoma. Toxicol Appl Pharmacol 209: 183-191, 2005.

14. Piao BK, Wang YX, Xie GR, et al: Impact of complementary mistletoe extract treatment on quality of life in breast, ovarian and non-small cell lung cancer patients. A prospective randomized controlled clinical trial. Anticancer Res 24: 303-309, 2004.

15. Powell CB, Fung P, Jackson J, et al: Aqueous extract of herba Scutellaria barbatae, a Chinese herb used for ovarian cancer, induces apoptosis of ovarian cancer cell lines. Gynecol Oncol 91: 332-340, 2003. 